\title{
The Importance of the Occlusal Plane in Predicting Better Facial Soft Tissue in Class II Malocclusion in Ethnic Javanese
}

\author{
I. Gusti Aju Wahju Ardani ${ }^{1} \quad$ Floretta Charlene Dinata ${ }^{1}$ Ari Triwardhani ${ }^{1}$ \\ ${ }^{1}$ Department of Orthodontic, Faculty of Dental Medicine, \\ Address for correspondence I. Gusti Aju Wahju Ardani, DDS, MSc, PhD \\ Department of Orthodontic, Faculty of Dental Medicine, Universitas \\ Airlangga, Campus A, Jl Prof Dr Moestopo, No. 47, Surabaya 60132, \\ East Java, Indonesia (e-mail: wahju_ardani@fkg.unair.ac.id).
}

Eur J Dent:2020;14:429-434

\begin{abstract}
Objectives Class II malocclusion is largely due to a retrognathic mandible. Mandibular rotation is closely related to changes in the occlusal plane during growth. The problems in the occlusal plane could cause disadvantages in the soft tissue profile in Class II malocclusion, presenting treatment challenges for an orthodontist. This study aimed to investigate the importance of the occlusal plane for a better soft tissue profile in Class II malocclusion for Javanese patients.

Materials and Methods The total number of cephalogram softcopies of patients with skeletal Class II malocclusion were selected based on ANB values ( $>4$ degrees), no agenesis teeth except the third molar, and all permanent teeth. The cephalograms were calculated using digital tracing by Morpheus 3D imaging. The points and areas to be analyzed on the cephalogram were predetermined. The examination was performed in a span of 1 month and performed via a statistical test using Pearson's test and multiple regression analysis $(p<0.05)$.

Keywords

- skeletal Class II malocclusion

- occlusal plane

- soft tissue

- facial profile

- cephalometric

Results There were significant correlation values between the angles produced by the occlusal plane to sella national, Frankfurt horizontal, mandibular plane, and Z-angle $(p<0.05)$.

Conclusion Patients with skeletal Class II malocclusion have a significant correlation between the occlusal plane and the vertical plane, thereby affecting the shape of the soft tissue profile, which causes a facial imbalance. By improving mandibular movement, the soft tissue profile can also be corrected.
\end{abstract}

\section{Introduction}

A Class II skeletal malocclusion has a $15 \%$ presentation in the world's population, and most of the cases encountered are the angle Class II division 1. This malocclusion is accompanied by skeletal discrepancies between the mandible and the maxilla, the protrusion of maxilla, the retrusion of the mandible, or a combination of both. ${ }^{1}$ The characteristics of Class II division 2 are often accompanied by severe deep bite, maxillary and mandible central incisive inclination toward the lingual, as well as a lateral incisive of maxilla inclination toward the labial. ${ }^{2}$
Generally, in cephalometrics, a Class II malocclusion with anteroposterior skeletal discrepancy has a characteristic of large ANB calculation, indicating an unfavorable relationship between the upper and lower jaws. An anteroposterior skeletal discrepancy is usually accompanied by vertical discrepancies, such as a shorter anterior face. ${ }^{3,4}$ The occlusal plane refers to an imaginary surface that is anatomically related to the cranium. Theoretically, it touches the incisal edges of the incisors and the tips of the occluding surfaces of the posterior teeth (first molar). The occlusal plane is the plane established if a line was drawn through all the buccal cusp tips and incisal edges of the mandibular teeth and then 
broadened into a plane to include the lingual cusp tips, continuing across the arch to include the buccal and lingual cusp tips of the opposite side.

Soft tissue becomes one of the factors causing Class II malocclusions, such as in the case of Class II division 1, causing a hypotonic upper lip or retrusion of lower jaw incisors due to a hyperactive lower lip. ${ }^{6}$ Mandibular rotation is closely related to occlusal plane changes during growth. Previous research has observed continuous horizontal changes of the occlusal plane accompanied by a reduction of the mandible during growth and development. This suggests that changes in the occlusal plane may affect the growth pattern of Class II skeletal malocclusion. ${ }^{7}$ The aim of this study is to investigate the importance of the occlusal plane to predict a better soft tissue profile in Class II malocclusion for Javanese patients.

\section{Materials and Methods}

\section{Sample}

The number of malocclusion samples obtained from the Faculty of Dental Medicine, Airlangga University Dental Hospital in 2017 to 2018 was 233 patients. No patient included had previous orthodontic treatment, with Class I malocclusions (ANB $=1-3$ degrees) of 124 people $(53.22 \%$ ), Class II (ANB $\geq 4$ degrees) with 63 people (27.04\%), and Class III (ANB $\leq 0$ degrees) with 46 people (19.74\%).

In this study, Class II malocclusions were adjusted according to predetermined criteria. Inclusion criteria of sample selection include Javanese individuals, aged between 15 and 35 years old, and complete permanent dentition, as well as ANB $\geq 4$ degrees. Beside the ANB, we added the $Y$-axis $\geq 65.5$ degrees and facial axis $\geq 90$ degrees. Exclusion criteria of samples selection include a history of orthodontic treatment, dentofacial trauma or temporomandibular joint disorders, genetic syndrome, missing teeth, and supernumerary teeth. After selection, we had a total of 51 samples wherein 10 samples were male and 41 samples were female. The confidentiality of the patient's identity remained protected, and, for patients younger than 17 years, informed consent was represented by their parents.

Lateral cephalometric was then taken for each patient in the natural head position while the patient closed their teeth in centric occlusion and lips were in a relaxed position. Cephalometric analysis was performed using Morpheus 3D Imaging (digital tracing cephalogram; Morpheus Co., Ltd., Gyeonggi-do, Korea) digital cephalometric by a single exam-

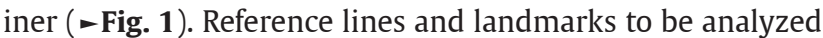
included:

1. SNA: Angle formed from the points sella $(\mathrm{S})$, nasion $(\mathrm{N})$, and $A$.

2. SNB: Angle formed from the points $\mathrm{S}, \mathrm{N}$, and $\mathrm{B}$.

3. ANB: Angle between SNA and SNB.

4. FMA: Angle formed by extending mandibular plane to the Frankfort horizontal (FH) plane.

5. FMIA: Angle formed by extending mandibular incisor long axis to the $\mathrm{FH}$ plane.

6. IMPA: Angle formed by extending lower incisor long axis to the mandibular plane.

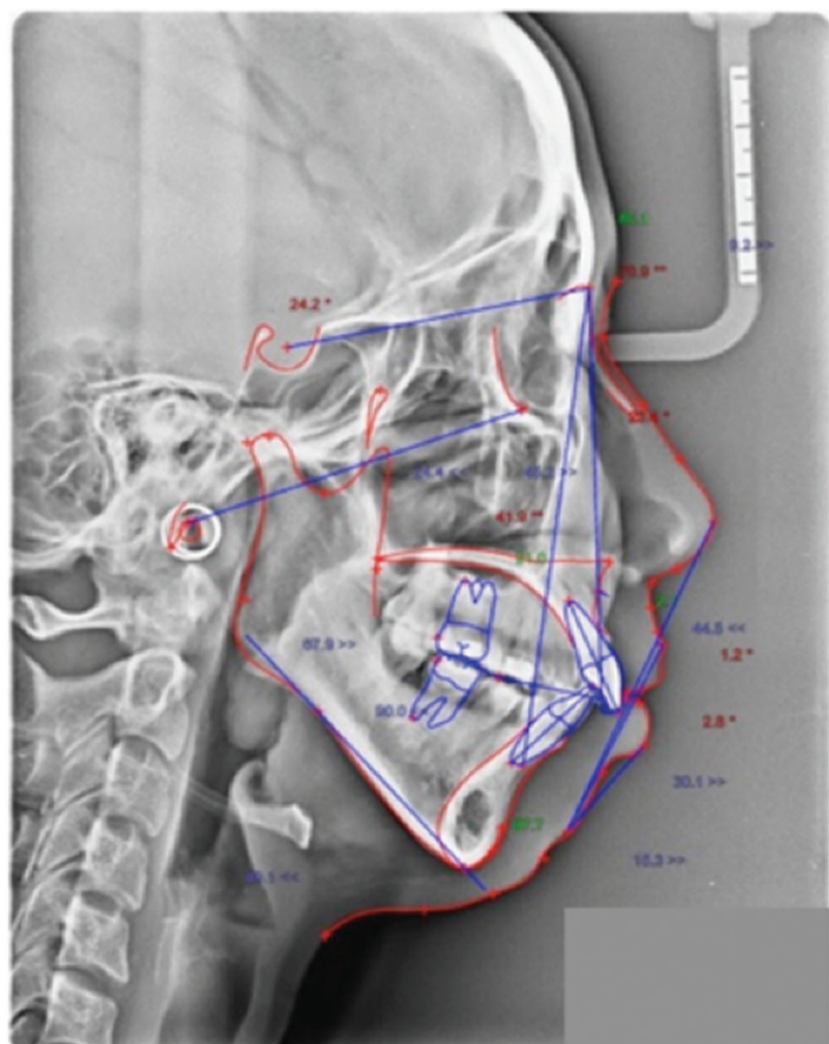

Fig. 1 Digital cephalometric analysis performed using Morpheus 3D.

7. OCC-SN: Angle formed by occlusal plane to sella-nasion plane.

8. OCC-FH: Angle formed by occlusal plane to the FH plane.

9. OCC-MP: Angle formed by occlusal plane to the mandibular plane.

10. Z-angle: Angle formed by the FH plane and profile line (line formed by touching chin and lower lip).

11. Go angle: Angle formed from the points articulare (Ar), Go, and menton (Me).

12. Y-axis: Angle formed from the $\mathrm{FH}$ plane with the S-gnathion line, used to determine the direction of mandibular growth.

13. Facial axis: Angle between basion to nasion and posterosuperior aspect of pterygomaxillary fissure to constructed gnathion.

\section{Statistical Analysis}

The mean and standard deviation (SD) of the measurements were determined using Statistical Package for Social Science 17.0 (SPSS Inc.; Chicago, Illinois, United States). The data normality was calculated using Kolmogorov-Smirnov' test and Shapiro-Wilk's test $(p>0.05)$, while the correlation between each variable was analyzed using the Pearson's correlation test and multiple regression analysis $(p<0.05)$.

\section{Results}

A normality test is a test conducted with the aim to assess the distribution of data in a group of data or variables ( - Table $\mathbf{1}$ ). 
After the normality test was done, we calculated the mean and SD for the data ( - Table 2 ). In this statistical table, there was no correlation between SNA and Z-angle, OCC-MP, Go angle, $Y$-axis, and facial axis, but we detected a negative correlation with OCC-SN and OCC-FH. There was a positive correlation of SNB with the Z-angle and a negative correlation for OCC-SN and OCC-FH. There was no ANB correlation with OCC-FH, OCC-MP, Go angle, $Y$-axis, and facial axis, but there was a positive correlation of OCC-SN and a negative correlation with the Z-angle. There was a positive correlation of FMA with OCC-SN and OCC-FH and a negative correlation with the Z-angle, whereas FMIA has a negative correlation with OCC-SN and OCC-FH and positive correlation with the Z-angle. No correlation was found from IMPA with the predetermined parameters (- Table $\mathbf{3}$ ).
There was a positive correlation of OCC-SN to OCC-MP, Go angle, and $Y$-axis, while negative correlations were found for the Z-angle and facial axis, while OCC-FH did not have a correlation with OCC-SN, OCC-MP, and Go angle; however, it has a negative correlation with the Z-angle and facial axis, and a positive correlation with the $Y$-axis. In OCC-MP, a significant correlation was obtained in the parameters of OCC-FH, Go angle, $Y$-axis, and facial axis.

There was a negative correlation between the Z-angle and OCC-SN, OCC-FH, OCC-MP, Go, and Y-axis, and a positive correlation with the Z-angle (up) and facial axis. In the $\mathrm{Z}$-angle, there was no correlation with OCC-MP, but there was a negative correlation with OCC-SN, OCC-FH, Go angle, and $Y$-axis, and a positive correlation with the Z-angle (low) and facial axis.

Table 1 Normality test result

\begin{tabular}{|l|l|l|l|l|l|l|l|}
\hline \multirow{2}{*}{} & \multicolumn{3}{|c|}{ Tests of normality } \\
\cline { 2 - 7 } & Statistic & df & Significance & Statistic & df & Significance \\
\hline SNA & 0.093 & 51 & $0.200^{\text {a }}$ & 0.965 & 51 & 0.137 \\
\hline SNB & 0.106 & 51 & $0.200^{\text {a }}$ & 0.978 & 51 & 0.471 \\
\hline ANB & 0.058 & 51 & $0.200^{\text {a }}$ & 0.993 & 51 & 0.99 \\
\hline FMA & 0.099 & 51 & $0.200^{\text {a }}$ & 0.965 & 51 & 0.133 \\
\hline FMIA & 0.076 & 51 & $0.200^{\text {a }}$ & 0.985 & 51 & 0.744 \\
\hline IMPA & 0.078 & 51 & $0.200^{\text {a }}$ & 0.983 & 51 & 0.685 \\
\hline OCC-FH & 0.133 & 51 & 0.026 & 0.959 & 51 & 0.076 \\
\hline OCC-SN & 0.085 & 51 & $0.200^{\text {a }}$ & 0.98 & 51 & 0.547 \\
\hline OCC-MP & 0.15 & 51 & 0.006 & 0.904 & 51 & 0.001 \\
\hline Z angle & 0.1 & 51 & $0.200^{\text {a }}$ & 0.957 & 51 & 0.064 \\
\hline Go angle & 0.083 & 51 & $0.200^{\text {a }}$ & 0.976 & 51 & 0.375 \\
\hline Y-axis & 0.109 & 51 & 0.187 & 0.978 & 51 & 0.444 \\
\hline Facial axis & 0.088 & 51 & $0.200^{\text {a }}$ & 0.981 & 51 & 0.567 \\
\hline
\end{tabular}

aThis is a lower bound of the true significance.

Note: Lilliefors significance correction.

Table 2 Mean, SD, and normal values of each variable

\begin{tabular}{|l|l|l|l|l|}
\hline Variable & Minimum & Maximum & Mean \pm SD & Normal \\
\hline SNA (deg) & 75.72 & 88.26 & $82.1 \pm 3.53$ & 84.3 \\
\hline SNB (deg) & 66.63 & 85.71 & $75.4 \pm 4.07$ & 81.4 \\
\hline ANB (deg) & 0.98 & 11.81 & $6.7 \pm 2.09$ & \pm 2.9 \\
\hline FMA (deg) & 11.03 & 67.86 & $39.8 \pm 9.35$ & 25 \\
\hline FMIA (deg) & 17.91 & 58.5 & $39.8 \pm 9.15$ & 65 \\
\hline IMPA (deg) & 86.55 & 118.21 & $100.4 \pm 7.59$ & 90 \\
\hline OCC-SN (deg) & 9.97 & 45.19 & $25.8 \pm 6.4$ & 14 \\
\hline OCC-FH (deg) & 2.69 & 27.91 & $16.6 \pm 5.7$ & 9.3 \\
\hline OCC-MP (deg) & 14.06 & 29.14 & $14.8 \pm 4.6$ & 15 \\
\hline Z-angle & 20.63 & 74.69 & $54.7 \pm 11.7$ & \pm 75 \\
\hline Go angle (deg) & 95.32 & 137.89 & $76.5 \pm 6.93$ & 119 \\
\hline Y-axis (deg) & 59.61 & 90.47 & $78.78 \pm 5.86$ & 65.5 \\
\hline Facial axis (deg) & 66.3 & 91.76 & 90.0 \\
\hline
\end{tabular}

Abbreviation: SD, standard deviation. 
Table 3 Statistical calculation result of Pearson and multiple regression analysis

\begin{tabular}{|c|c|c|c|c|c|c|c|c|c|c|c|c|c|}
\hline Pearson & $\begin{array}{l}\text { SNA } \\
\text { (deg) }\end{array}$ & $\begin{array}{l}\text { SNB } \\
\text { (deg) }\end{array}$ & $\begin{array}{l}\text { ANB } \\
\text { (deg) }\end{array}$ & $\begin{array}{l}\text { FMA } \\
\text { (deg) }\end{array}$ & $\begin{array}{l}\text { FMIA } \\
\text { (deg) }\end{array}$ & $\begin{array}{l}\text { IMPA } \\
\text { (deg) }\end{array}$ & $\begin{array}{l}\text { OCC-SN } \\
\text { (deg) }\end{array}$ & $\begin{array}{l}\text { OCC-FH } \\
\text { (deg) }\end{array}$ & $\begin{array}{l}\text { OCC-MP } \\
\text { (deg) }\end{array}$ & Z-angle & $\begin{array}{l}\text { Go } \\
\text { angle } \\
\text { (deg) }\end{array}$ & $\begin{array}{l}Y \text {-axis } \\
\text { (deg) }\end{array}$ & $\begin{array}{l}\text { Facial } \\
\text { axis }\end{array}$ \\
\hline \multirow{2}{*}{$\begin{array}{l}\text { SNA } \\
\text { (deg) }\end{array}$} & \multirow[t]{2}{*}{-} & $859^{\mathrm{a}}$ & 0.017 & $-0.401^{\mathrm{a}}$ & $0.332^{\mathrm{b}}$ & 0.093 & $-0.444^{a}$ & $-0.413^{a}$ & 0.244 & 0.130 & 0.248 & 0.245 & 0.250 \\
\hline & & 0.000 & 0.908 & 0.004 & 0.017 & 0.516 & 0.001 & 0.003 & 0.085 & 0.362 & 0.079 & 0.083 & 0.076 \\
\hline \multirow{2}{*}{$\begin{array}{l}\text { SNB } \\
\text { (deg) }\end{array}$} & $0.859^{a}$ & \multirow[t]{2}{*}{-} & $-0.498^{a}$ & $-0.493^{a}$ & $0.510^{\mathrm{a}}$ & -007 & $-0.586^{a}$ & $-0.374^{a}$ & 0.220 & $0.361^{\mathrm{a}}$ & 0.229 & -0.225 & 0.232 \\
\hline & 0.000 & & 0.000 & 0.000 & 0.000 & 0.961 & 0.000 & 0.007 & 0.120 & 0.009 & 0.107 & 0.112 & 0.101 \\
\hline \multirow{2}{*}{$\begin{array}{l}\text { ANB } \\
\text { (deg) }\end{array}$} & 0.017 & $-0.498^{a}$ & \multirow[t]{2}{*}{ - } & $0.284^{b}$ & $-0.433^{a}$ & 0.171 & $0.393^{\mathrm{a}}$ & 0.134 & -0.018 & $-0.483^{a}$ & -0.026 & 0.025 & -0.029 \\
\hline & 0.908 & 0.000 & & 0.043 & 0.002 & 0.229 & 0.004 & 0.348 & 0.903 & 0.000 & 0.854 & 0.863 & 0.838 \\
\hline \multirow{2}{*}{$\begin{array}{l}\text { FMA } \\
\text { (deg) }\end{array}$} & $-0.401^{a}$ & $-0.493^{a}$ & 0.284 & \multirow[t]{2}{*}{ - } & $-0.664^{a}$ & $-432^{a}$ & $0.630^{\mathrm{a}}$ & $0.654^{\mathrm{a}}$ & -0.219 & $-0.608^{a}$ & -0.240 & -0.238 & -0.248 \\
\hline & 0.004 & 0.000 & 0.043 & & 0.000 & 0.002 & 0.000 & 0.000 & 0.122 & 0.000 & 0.090 & 0.092 & 0.080 \\
\hline \multirow{2}{*}{$\begin{array}{l}\text { FMIA } \\
\text { (deg) }\end{array}$} & $0.332^{b}$ & $0.510^{\mathrm{a}}$ & $-0.433^{a}$ & $-0.664^{a}$ & \multirow[t]{2}{*}{ - } & $-0.387^{a}$ & $-0.637^{a}$ & $-0.579^{a}$ & 0.191 & $0.674^{a}$ & 0.197 & 0.194 & 0.201 \\
\hline & 0.017 & 0.000 & 0.002 & 0.000 & & 0.005 & 0.000 & 0.000 & 0.180 & 0.000 & 0.167 & 0.172 & 0.156 \\
\hline \multirow{2}{*}{$\begin{array}{l}\text { IMPA } \\
\text { (deg) }\end{array}$} & 0.093 & -0.007 & 0.171 & $0.432^{\mathrm{a}}$ & $-0.387^{a}$ & \multirow[t]{2}{*}{-} & -0.007 & -0.107 & 0.040 & -0.064 & 0.059 & 0.059 & 0.062 \\
\hline & 0.516 & 0.961 & 0.229 & 0.002 & 0.005 & & 0.959 & 0.453 & 0.779 & 0.657 & 0.680 & 0.679 & 0.663 \\
\hline \multirow{2}{*}{$\begin{array}{l}\text { OCC-SN } \\
\text { (deg) }\end{array}$} & $-0.444^{a}$ & -0.586 & $0.393^{\mathrm{a}}$ & $0.630^{\mathrm{a}}$ & $-0.637^{a}$ & -0.007 & \multirow[t]{2}{*}{ - } & 0.233 & $0.438^{a}$ & $-0.497^{a}$ & $0.472^{\mathrm{a}}$ & $0.510^{\mathrm{a}}$ & $-0.643^{a}$ \\
\hline & 0.001 & 0.000 & 0.002 & 0.000 & 0.000 & 0.479 & & 0.100 & 0.001 & 0.000 & 0.000 & 0.000 & 0.000 \\
\hline \multirow{2}{*}{$\begin{array}{l}\text { OCC-FH } \\
\text { (deg) }\end{array}$} & -0.339 & $-0.408^{a}$ & 0.224 & $0.654^{\mathrm{a}}$ & $-0.579^{a}$ & -0.107 & 0.263 & \multirow[t]{2}{*}{-} & -0.234 & $-0.398^{a}$ & 0.256 & $0.741^{\mathrm{a}}$ & $-0.496^{a}$ \\
\hline & 0.008 & 0.001 & 0.057 & 0.000 & 0.000 & 0.227 & 0.063 & & 0.099 & 0.004 & 0.069 & 0.000 & 0.000 \\
\hline \multirow{2}{*}{$\begin{array}{l}\text { OCC-MP } \\
\text { (deg) }\end{array}$} & -0.126 & -0.208 & 193 & $534^{a}$ & -183 & $-439^{a}$ & -0.033 & $-0.288^{b}$ & \multirow[t]{2}{*}{-} & 0.068 & $0.999^{\mathrm{a}}$ & $0.999^{\mathrm{a}}$ & $0.999^{a}$ \\
\hline & 0.189 & 0.071 & 087 & 0.000 & 0.100 & 0.001 & 0.818 & 0.041 & & 0.638 & 0.000 & 0.000 & 0.000 \\
\hline \multirow[t]{2}{*}{ Z-angle } & 0.130 & 0.361 & -0.483 & 0.608 & 0.674 & -0.064 & $-0.497^{a}$ & $-0.398^{a}$ & $-0.284^{b}$ & \multirow[t]{2}{*}{ - } & $-0.419^{a}$ & $-0.569^{a}$ & $0.598^{a}$ \\
\hline & 0.181 & 0.005 & 0.000 & 0.000 & 0.000 & 0.329 & 0.000 & 0.004 & 0.044 & & 0.002 & 0.000 & 0.000 \\
\hline \multirow{2}{*}{$\begin{array}{l}\text { Go } \\
\text { angle } \\
\text { (deg) }\end{array}$} & -0.124 & -0.184 & 0.141 & 0.744 & $-0.397^{a}$ & $-0.438^{a}$ & $0.472^{\mathrm{a}}$ & 0.256 & $0.696^{a}$ & $-0.419^{a}$ & \multirow[t]{2}{*}{ - } & $0.411^{\mathrm{a}}$ & $-0.491^{a}$ \\
\hline & 0.387 & 0.197 & 0.323 & 0.395 & 0.004 & 0.001 & 0.000 & 0.069 & 0.000 & 0.002 & & 0.003 & 0.000 \\
\hline \multirow{2}{*}{$\begin{array}{l}Y \text {-axis } \\
\text { (deg) }\end{array}$} & -0.537 & -0.609 & 0.235 & 0.874 & 0.641 & -0.304 & $0.510^{\mathrm{a}}$ & $0.741^{\mathrm{a}}$ & $0.303^{b}$ & $-0.569^{a}$ & $0.411^{\mathrm{a}}$ & \multirow[t]{2}{*}{ - } & $-0.689^{a}$ \\
\hline & 0.477 & 0.208 & 0.096 & 0.558 & 0.402 & 0.030 & 0.000 & 0.000 & 0.031 & 0.000 & 0.003 & & 0.000 \\
\hline \multirow{2}{*}{$\begin{array}{l}\text { Facial } \\
\text { axis }\end{array}$} & $0.466^{\mathrm{a}}$ & 0.683 & $-0.513^{a}$ & 0.770 & 0.618 & 0.205 & $-0.643^{a}$ & $-0.496^{a}$ & $-0.451^{a}$ & $0.598^{\mathrm{a}}$ & $-0.491^{a}$ & $-0.689^{a}$ & \multirow[t]{2}{*}{-} \\
\hline & 0.001 & 0.830 & 0.000 & 0.391 & 0.138 & 0.150 & 0.000 & 0.000 & 0.001 & 0.000 & 0.000 & 0.000 & \\
\hline
\end{tabular}

A positive correlation was found between Go angle and OCC-SN, OCC-MP, and $Y$-axis, while negative correlations were discovered between the $\mathrm{Z}$-angle and facial axis. The $Y$-axis has a correlation with OCC-SN, OCC-FH, OCC-MP, and Go, while there was a negative correlation with the Z-angle and facial axis. In addition, the facial axis has a positive correlation with Z-angle and negative correlation with OCC-SN, OCC-FH, OCC-MP, Go angle, and Y-axis.

\section{Discussion}

At the beginning of the 20th century, the primary goal of orthodontic treatment was to achieve normal occlusion. However, soft tissue is the primary determinant of a patient's facial appearance. After a paradigm shift, orthodontists now place more emphasis on the soft tissue outcomes of their treatments. Changes in the facial profile in a skeletal Class II malocclusion are very challenging for an orthodontist. Many factors need to be considered when treating adult patients, such as aesthetics, skeletal vertical dimensions, dentoalveolar protrusion, lip formation, facial convexity, and occlusion stability. ${ }^{8,9}$ Characteristics of Class II malocclusion include the protrusion of the upper jaw and upper lip, incompetent lip growth, poor chin morphology, and small nasolabial angles, which are often the main complaint of patients. ${ }^{10-12}$

Measurements in this study were divided into three parts: occlusal plane (OCC-SN, OCC-FH, and OCC-MP), facial balance and soft tissue profile (FMA, FMIA, IMPA, and $Z$-angle), and vertical plane of the face ( $Y$-axis and facial axis) as support. First, this study will discuss the relationship between SNA, SNB, and ANB with the occlusal plane (functional occlusal plane [FOP]). This field is used because FOP shows stability in orthodontic patients in a skeletal Class II or Class III malocclusions. ${ }^{13}$

It is known that SNA and SNB have a negative correlation with the occlusal plane of OCC-SN and OCC-FH. The mean value of SNA (82.1) is normal, while the SNB (75.4) is smaller than normal. According to Li et al, individuals with grade II skeletal malocclusions have mandibular retrusion, a finding consistent with McNamara (1984). ${ }^{13,14}$ SNB has a 
positive correlation with the Z-angle, while ANB has a negative correlation with the Z-angle. This is consistent with statements made by $\mathrm{Oh}$ et al and Amer et al in that a SNB that is small in value will affect the size of the Z-angle which becomes smaller than the normal size (normal 78, mean 56.7) and the larger ANB size ( $>40$, mean 6.7$)$. This greatly affects the balance of the face. ${ }^{15,16}$

Tweed (1964) noted that the relationship of the three measurement angles, namely, FMA, FMIA, and IMPA, provides information about the vertical shape of one's skeletal, mandibular incisor relation to basal bone, and the relative amount of protusion on the face. In an interview in December 1967, Tweed said that of these three measurement angles, FMIA is the most stable measurement because according to the research, FMIA calculations did not change during growth. In this study, a positive correlation was obtained from FMA with OCC-SN and OCC-FH, and FMIA with the $\mathrm{Z}$-angle. This could be interpreted as the greater the value of the FMA, the greater the value of OCC-SN and OCC-FH, as well as FMIA, the greater the value, the greater the value of the Z-angle. Negative correlations were obtained for FMA against the Z-angle and FMIA against OCC-SN and OCC-FH, with the understanding that the greater the FMA value, the smaller the value of the $Z$-angle drift, and the greater the FMIA value, the greater the OCC-SN and OCC-FH values. ${ }^{17,18}$

For practitioners, changing the problematic occlusal plane in patients is the ultimate goal in an orthodontic treatment, whereas for patients, the change of facial profile becomes more important. ${ }^{8}$ A positive correlation of OCC-SN to OCC-MP and a negative correlation of OCC-MP to OCC-FH were obtained. There is also a negative correlation of OCC-SN and OCC-FH on the Z-angle and facial axis, while there was a positive correlation for the OCC-SN and OCC-FH on the Y-axis. According to Kim et al, skeletal Class II malocclusion reveals a close relationship between the occlusal and vertical fields, as in this study. In addition, Kim et al added that this could be known from an early stage of growth and development. ${ }^{19}$

The mean value of the Z-angle (54.7) is below average and positively correlated with the facial axis but negatively correlated with OCC-SN, OCC-FH, OCC-MP, Go angle, and Y-axis. According to this study, changes in the occlusal plane affect changes in the soft tissue, thus allowing a prediction of a better facial profile. ${ }^{10}$

Ricketts determined the growth of the mandible arch as a guide for predicting the growth of the mandible.. ${ }^{20,21}$ The gonial angle position moves toward the posterior, a distance that equals almost half of the total increase in mandibular growth. ${ }^{20}$ In this study, the gonial angle does not have a correlation with OCC-FH but does reveal a positive correlation with OCC-SN, OCC-MP, and $Y$-axis, and a negative correlation with the $Z$-angle and facial axis. This shows that the greater value of the gonial angle, the greater value of OCC-SN, OCC-MP, and $Y$-axis and the smaller value of the Z-angle and facial axis.. ${ }^{21}$

McNamara noted that excessive vertical development is indicated by negative values ( $<90$ degrees), while less vertical facial development is indicated by positive values (>90 degrees), which are obtained by measuring the basion angle-PTM-gnathion and are expected to have an upright position on the face when balanced. In this study, the vertical plane of the face is represented by the $Y$-axis and facial axis. The $Y$-axis has a positive correlation with OCC-SN, OCC-FH, OCC-MP, and Go angle, but a negative correlation with the Z-angle and facial axis. However, the facial axis has a positive correlation only with the Z-angle and a negative correlation with OCC-SN, OCC-FH, OCC-MP, Go angle, and $Y$-axis. ${ }^{14,22}$

According to previous studies, such as those conducted by Sharma and Xin, gender variations do not have a significant effect on the skeletal and dental components of Class II malocclusions. Likewise, in this study, gender variations did not affect the calculations performed. ${ }^{23}$

\section{Conclusion}

Based on this study, we can conclude that there is a correlation between the occlusal plane to the soft tissue profile and facial balance in ethnic Javanese malocclusion patient. Patients with Class II skeletal malocclusions in ethnic Javanese reveal a significant correlation between the occlusal plane and Z-angle, thereby affecting the shape of the soft tissue profile, causing a disturbed facial balance. The occlusal plane is considered important in determining orthodontic diagnosis and treatment plans. Effective control and more attention to the occlusal plane in therapy can avoid unfavorable mandibular rotation and achieve a good facial profile. However, further research is needed to confirm the importance of the occlusal plane after orthodontic treatment for better prognosis.

\section{Conflict of Interest}

None declared.

\section{References}

1 Irawan R, Suparwitri S, Hardjono S. Perawatan Maloklusi Angle Kelas II Divisi 1 Menggunakan Bionator Fungsional. Maj Ked Gi 2014;21(1):97-101

2 Utari TR. Perawatan Maloklusi Angle kelas II divisi 2 Pasien Dewasa dengan Pencabutan Dua Premolar Atas. Maj Ked Gi 2017;3(1):51-58

3 Bishara SE, Class II. Malocclusions: diagnostic and clinical considerations with and without treatment. Semin Orthod 2006;12(1):11-24

4 Ye R, Li Y, Li X, et al. Occlusal plane canting reduction accompanies mandibular counterclockwise rotation in camouflaging treatment of hyperdivergent skeletal Class II malocclusion. Angle Orthod 2013;83(5):758-765

5 Şenışık NE, Hasipek S. Occlusal cant: etiology, evaluation, and management. Turkish J Orthod 2015;27(4):174-180

6 Rehan A, Iqbal R, Ayub A, Ahmed I. Soft tissue analysis in Class I and Class II skeletal malocclusion in patients reporting to Department of Orthodontics, Khyber College of Dentistry, Pershawar. Pak Oral Dent J 2014;34(1):87-90

7 Tanaka EM, Sato S. Longitudinal alteration of the occlusal plane and development of different dentoskeletal frames during growth. Am J Orthod Dentofacial Orthop 2008;134(5):602. e1-602.e11, discussion 602-603 
8 Ozzeybek Can FS, Turkkahraman H. Effects of rapid maxillary expansion and facemask therapy on the soft tissue profiles of Class III patients at different growth stages. Eur J Dent 2019;13(2):143-149

9 Gaur A, Maheshwari S, Verma SK. Correction of Class II malocclusion and soft tissue profile in an adult patient. Contemp Clin Dent 2016;7(3):382-385

10 Xuan J, Bing L, Li SF, Ma YM, Kwon TG, Wu XP. Morphological characteristics of soft tissue profile of angle's class II division 1 malocclusion before and after orthodontic treatment. Int J Morphol 2018;36(1):26-30

11 Halimi A, Azeroual MF, Abouqal R, Zaoui F. A comparative study of the transverse dimensions of the dental arches between Class I dental occlusion and Class II 1 and Class II2 malocclusions [in French]. Odontostomatol Trop 2011;34(136):47-52

12 Gandhi V, Mehta F, Joshi H. Treatment of class II malocclusion and impacted canines with two-phase orthodontic treatment. Contemp Clin Dent 2017;8(1):161-166

13 Li JL, Kau C, Wang M. Changes of occlusal plane inclination after orthodontic treatment in different dentoskeletal frames. Prog Orthod 2014;15(1):41

14 McNamara JA Jr. A method of cephalometric evaluation. Am J Orthod 1984;86(6):449-469

15 Oh HS, Korn EL, Zhang X, et al. Correlations between cephalometric and photographic measurements of facial attractiveness in Chinese and US patients after orthodontic treatment. Am J Orthod Dentofacial Orthop 2009;136(6):762.e1-762.e14, discussion 762-763
16 Amer ME, Labib A, Hassan A. Correlations between lateral cephalometric and facial attractiveness of Egyptian adolescents. IOSR J Dental Med Sci 2015;14(10):80-88

17 Tweed CH, Brandt S. J Clin Orth Interview Part 2. 1968;2(1): $11-20$

18 Jacobson A, Radiographic Cephalometry: From Basics to Videoimaging, 2nd ed. Birmingham: Quintessence Publishing Co, Inc; 2006

19 Kim JI, Akimoto S, Shinji H, Sato S. Importance of vertical dimension and cant of occlusal plane in craniofacial development. Int J Stomatol Occlusion Med 2009;2(3):114-121

20 De Rossi M, Stuani MBS, da Silva LAB. Cephalometric evaluation of vertical and anteroposterior changes associated with the use of bonded rapid maxillary expansion appliance. Dental Press J Orthod 2010;15:62-70

21 Ardani IGAW, Willyanti I, Narmada IB. Correlation between vertical components and skeletal Class II malocclusion in ethnic Javanese. Clin Cosmet Investig Dent 2018;10(10):297-302

22 Ardani IGAW, Sanjaya ML, Sjamsudin J. Cephalometric characteristic of skeletal class II malocclusion in Javanese population at Universitas Airlangga Dental Hospital. Contemp Clin Dent 2018;9(Suppl 2) :S342-S346

23 Sharma BP, Xin C. Comparative cephalometric analysis of angle Class II division 1 malocclusion between Chinese male and female subjects. Orthodontic J Nepal 2014;4(2):21-23 